\title{
Synthesis of Substituted Indene Derivatives via Silver-catalyzed Annulative 1:1 Coupling of Secondary Benzyl Alcohols with Alkynes
}

Hideaki Morisaka ,Keishi Hirosawa ,Yasuhito Inai ,Yoshinosuke Usuki, Tetsuya Satoh

\begin{tabular}{|c|l|}
\hline Citation & Chemistry Letters. 50(3); 456-458 \\
\hline Issue Date & $2020-12-08$ \\
\hline Type & Journal Article \\
\hline Textversion & author \\
\hline $\begin{array}{c}\text { Supporting } \\
\text { Information }\end{array}$ & Supporting Information is available on $\underline{\text { https://doi.org/10.1246/cl.200846. }}$ \\
\hline Rights & $\begin{array}{l}\text { C } 2020 \text { The Chemical Society of Japan. The following article has been accepted by } \\
\text { Chemistry Letters. This is the accepted manuscript version. After it is published, it } \\
\text { will be found at https://doi.org/10.1246/cl.200846. }\end{array}$ \\
\hline DOI & $10.1246 / c l .200846$ \\
\hline
\end{tabular}

\section{Self-Archiving by Author(s)}

Placed on: Osaka City University Repository 


\title{
Synthesis of Substituted Indene Derivatives via Silver-Catalyzed Annulative 1:1 Coupling of Secondary Benzyl Alcohols with Alkynes
}

\author{
Hideaki Morisaka, Keishi Hirosawa, Yasuhito Inai, Yoshinosuke Usuki, and Tetsuya Satoh* \\ ${ }^{1}$ Department of Chemistry, Graduate School of Science, Osaka City University, 3-3-138 Sugimoto, Sumiyoshi-ku, Osaka 558-8585
}

The annulative coupling of secondary benzyl alcohols with internal alkynes efficiently proceeds in the presence of a silver catalyst. The reaction gives 1,2,3-substituted indene derivatives selectively as $1: 1$ coupling products. The procedure provides a straightforward synthetic route to indenes from readily available starting materials upon treatment with a simple reaction system under mild conditions. Keywords: silver catalyst; annulative coupling; indenes

Indene frameworks can be widely seen in naturally occurring and synthetic molecules possessing biological activities. ${ }^{1}$ Substituted indenes have also been utilized as functional ligand precursors in organometallic field. ${ }^{2}$ Therefore, the development of effective synthetic methods for constructing the important structures from readily available starting materials has been a significant subject in organic synthesis. ${ }^{3}$ Recently, indene synthesis by the annulative coupling of benzyl alcohols with alkynes has been achieved. ${ }^{4}$ Thus, Zhou's group reported the iron-catalyzed annulation of secondary benzyl alcohols with alkynes (Scheme 1). ${ }^{4 a}$ A number of 1,2,3-substituted indenes could be prepared by the method. However, especially in cases using electron-rich alcohols or electron-deficient alkynes, it was difficult to suppress further benzylation after annulation to predominantly form their 2:1 coupling products. Because of the applicability of $1,2,3$-substituted indenes as ligands, ${ }^{2 b-e}$ their synthetic methods with high selectivity has been still desired.

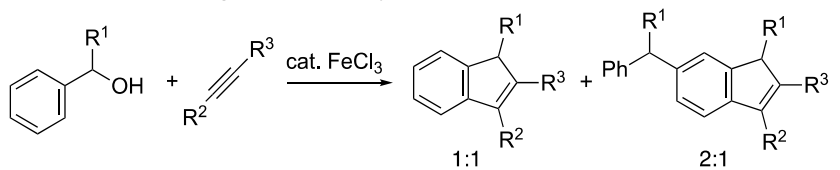

Scheme 1.

Meanwhile, benzyl alcohols have been recognized as promising substrates for transition-metal-catalyzed direct coupling. Their hydroxy function is known to act as a directing group, which leads to regioselective $\mathrm{C}-\mathrm{H}$ bond cleavage and functionalization at the ortho-position. ${ }^{5}$ During our study on the direct transformation of benzyl alcohols, ${ }^{6}$ we found that treatment of diphenylmethanol (1a) with diphenylacetylene (2a) in the presence of catalytic amounts of $\left[\mathrm{Cp}^{*} \mathrm{IrCl}_{2}\right]_{2}$ and $\mathrm{AgSbF}_{6}$ gives an annulative coupling product, 1,2,3-triphenyl-1H-indene (3aa) in $25 \%$ yield (Scheme 2). ${ }^{7}$ Unexpectedly, a similar amount of 3aa was obtained even in the absence of the iridium catalyst. In contrast to the previous iron-catalyzed reaction, ${ }^{4 a}$ no 2:1 coupling product was formed under conditions using $\mathrm{AgSbF}_{6}$ as a sole catalyst. Therefore, we examined the reaction system further and found that various 1,2,3-substituted indene derivatives can be prepared selectively under mild conditions (see below). The new findings are described herein.

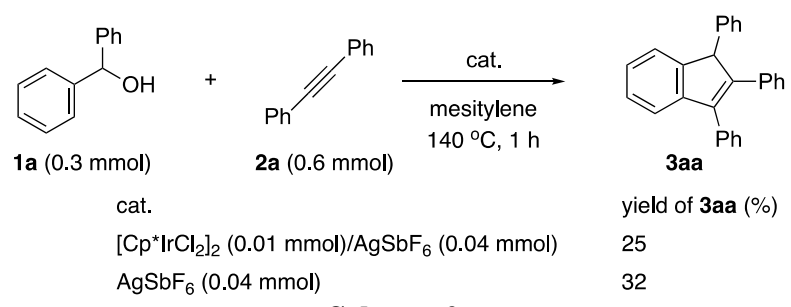

Scheme 2.

As described above, $\mathbf{1 a}(0.3 \mathrm{mmol})$ reacted with $\mathbf{2 a}(0.6$ mmol) in the presence of $\mathrm{AgSbF}_{6}(0.04 \mathrm{mmol})$ under argon in mesitylene $(2.5 \mathrm{~mL})$ at $140{ }^{\circ} \mathrm{C}$ for $1 \mathrm{~h}$ to afford 3aa in $32 \%$ yield (entry 1 in Table 1 ). The product yield was dramatically improved to $94 \%$ by decreasing the reaction temperature to 80 ${ }^{\circ} \mathrm{C}$ in 1,2-dichloroethane (entry 2). The reaction system composed of just substrates and a catalyst is simple, no other additives being required. Further decreasing the temperature to $60{ }^{\circ} \mathrm{C}$ slightly reduced the 3aa yield (entry 3). Decreasing amounts of $\mathbf{2 a}$ (entry 4 ) or $\mathrm{AgSbF}_{6}$ (entry 5) also reduced the yield. Other silver catalysts such as $\mathrm{AgBF}_{4}, \mathrm{AgNTf}_{2}$, and AgOAc showed poor activities (entries 6-8).

Table 1. Reaction of diphenylmethanol (1a) with diphenylacetylene $(\mathbf{2 a})^{\mathrm{a}}$

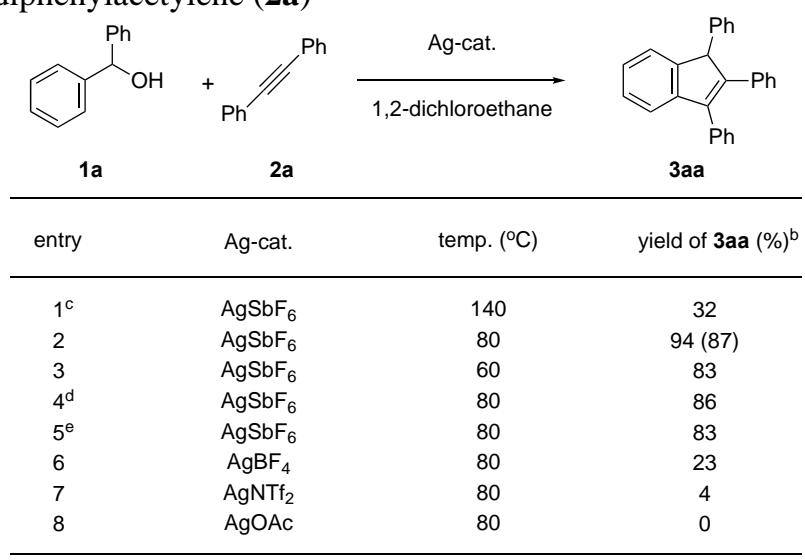

a Reaction conditions: 1 a $(0.3 \mathrm{mmol}), 2 a(0.6 \mathrm{mmol})$, Ag-cat. $(0.04 \mathrm{mmol})$ in 1,2dichloroethane $(2.5 \mathrm{~mL})$ under Ar for $1 \mathrm{~h}$, unless otherwise noted. ${ }^{\mathrm{b}} \mathrm{GC}$ yield based on the amount of $1 \mathrm{a}$ used. Value in parentheses indicates yield after purification. ${ }^{\mathrm{C}}$ In mesitylene $(2.5 \mathrm{~mL}) .{ }^{\mathrm{d}}$ With $2 \mathrm{a}(0.45 \mathrm{mmol}) .{ }^{e}$ With $\mathrm{AgSbF}_{6}(0.02$ $\mathrm{mmol})$.

Under the optimized conditions (entry 2 in Table 1), we examined the reactions using various alkynes $\mathbf{2}$ with $1 \mathrm{a}$ (Table 2). The reaction of electron-rich bis(4-methylphenyl)acetylene (2b) with 1a proceeded efficiently to produce $\mathbf{3 a b}$ in an almost quantitative yield, while that of electron-deficient bis(4-chlorophenyl)acetylene (2c) gave 3ac in a moderate yield. Note that even the latter case, no 2:1 coupling product was detected at all. It was previously reported that the reaction 
of $\mathbf{1 a}$ with electron-deficient alkynes such as $\mathbf{2 c}$ under $\mathrm{FeCl}_{3}$ catalysis tends to give 2:1 coupling products for relatively easier second benzylation. ${ }^{4 a}$ Unsymmetrical alkynes such as 1-phenyl-1-propyne (2d) and 1-phenyl-1-hexyne (2e) underwent the reaction with 1a regioselectively to give $\mathbf{3 a d}$ and 3ae in 71 and $69 \%$ yields, respectively. ${ }^{8,9}$

Next, the scope of benzyl alcohols was examined. The reactions of 4-methyl (1b) and -chloro (1c) substituted diphenylmethanols with $\mathbf{2 a}$ took place smoothly to produce the corresponding indenes 3ba and 3ca in 78 and $65 \%$ yields, respectively. Besides diphenylmethanols, 1-(4chlorophenyl)ethan-1-ol (1d) also underwent the annulation with 2a to produce 3da in a moderate yield. 1-(Naphthalen-2yl)ethan-1-ol (1e) also coupled with 2a to form tricyclic 3ea selectively.

Table 2. Reaction of benzyl alcohols 1 with alkynes $\mathbf{2}^{\mathrm{a}}$

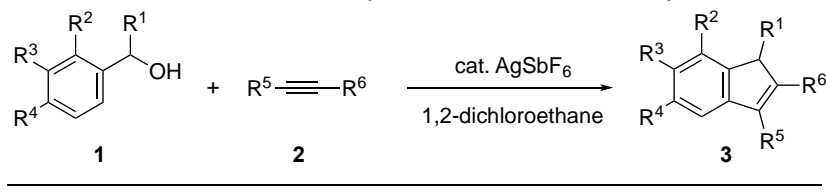

product yield $(\%)^{\mathrm{b}}$

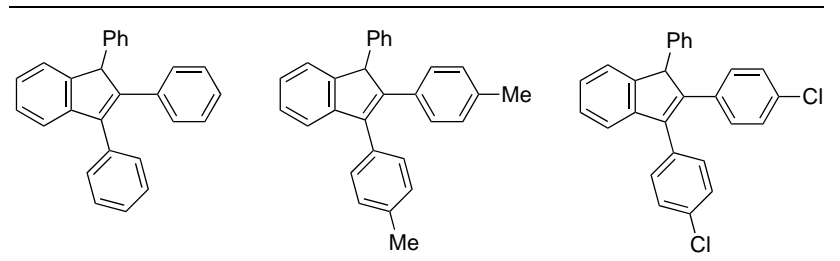

3aa $87 \%$ 3ab $97 \%$<smiles>CC1=C(c2ccccc2)c2ccccc2C1c1ccccc1</smiles>

3ad $71 \%$<smiles>Cc1ccc(C2C(c3ccccc3)=C(c3ccccc3)c3cc(C)ccc32)cc1</smiles>

3ba $78 \%$

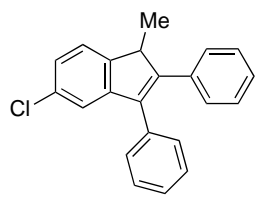

3da $45 \%$

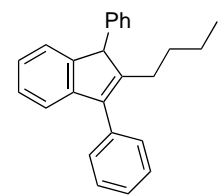

3ae $69 \%$

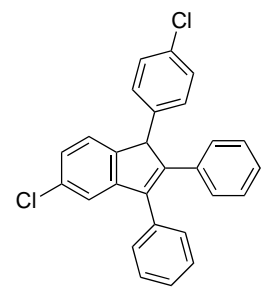

3ca $65 \%$

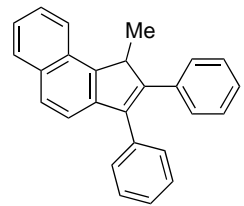

3ea $46 \%$ a Reaction conditions: 1 (0.3 mmol), 2 (0.6 mmol), AgSbF$_{6}(0.04 \mathrm{mmol})$ in 1,2dichloroethane $(2.5 \mathrm{~mL})$ under $\mathrm{Ar}$ at $80^{\circ} \mathrm{C}$ for $1 \mathrm{~h}$. ${ }^{\mathrm{b}}$ Isolated yield.

The present annulative coupling could be readily scaled up to a $1 \mathrm{mmol}$ scale. Thus, the reaction of $\mathbf{1 a}(1 \mathrm{mmol})$ with $\mathbf{2 a}(2 \mathrm{mmol})$ gave 3 aa in a reasonable yield $(256 \mathrm{mg}, 77 \%)$ (Scheme 3).

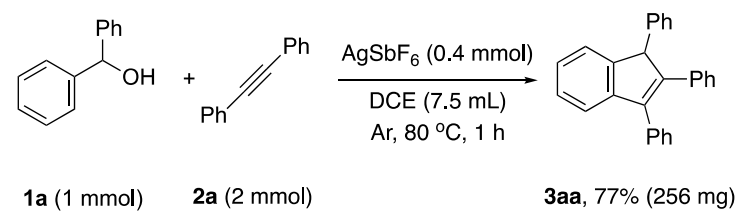

Scheme 3.

A plausible mechanism for the reaction of benzyl alcohols $\mathbf{1}$ with alkynes $\mathbf{2}$ is illustrated in Scheme 4. As proposed for the previous iron-catalyzed reaction, ${ }^{4} \mathrm{AgSbF}_{6}$ catalyst seems to activate the $\mathrm{C}-\mathrm{O}$ bond of $\mathbf{1}$ to form intermediate A. Then, annulation with $\mathbf{2}$ may take place to give intermediate $\mathbf{B}$. In the final deprotonation step, product $\mathbf{3}$ and $\mathrm{H}_{2} \mathrm{O}$ are formed to regenerate an active $\mathrm{Ag}^{+}$species.

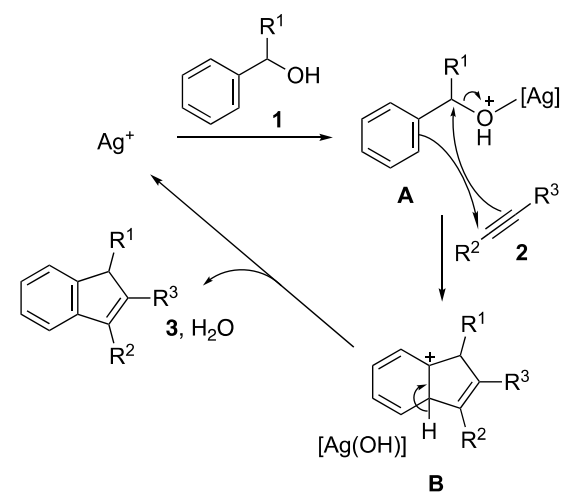

Scheme 4.

In summary, we have demonstrated that 1,2,3-substituted indene derivatives can be prepared selectively from readily available benzyl alcohols and alkynes. The annulative coupling reaction of these substrates proceeds smoothly under silver catalysis. Further work is underway for developing the procedure.

This work was partly supported by JSPS KAKENHI Grant Numbers 20H02745 and 18K19083 and OCU Strategic Research Grant 2020 for basic researches to T.S. and JSPS KAKENHI Grant Number JP18H04627 to Y.U.

Supporting Information is available electronically on $\mathrm{J}$ STAGE.

\section{References and Notes}

1 For selected reviews, see: a) Q. Deng, X. Meng, Chem. Asian J. 2020, 15, 2838. b) H. Gao, J. A. Katzenellenbogen, R. Garg, C. Hansch, Chem. Rev. 1999, 99, 723.

2 For example: a) C. M. B. Farr, A. M. Kazerouni, B. Park, C. D. Poff, J. Won, K. R. Sharp, M.-H. Baik, S. B. Blakey, J. Am. Chem. Soc. 20020, 142, 13996. b) S. Lee, H. Lei, T. Rovis, J. Am. Chem. Soc. 2019, 141, 12536. c) S. Raju, C. A. M. R. van Slagmaat, M. Lutz, H. Kleijn, J. T. B. H. Jastrzebski, M.-E. Moret, R. J. M. K. Gebbink, Eur. J. Inorg. Chem. 2017, 741. d) Q. Xi, W. Zhang, X. Zhang, Synlett 2006, 945. e) J. A. Ramsden, D. J. Milner, H. Adams, N. A. Bailey, P. D. Hempstead, C. White, J. Organomet. Chem. 1998, 551, 355. See also a review: f) B. M. Trost, M. C. Ryan, Angew. Chem. Int. Ed. 2017, 56, 2862.

3 For example: a) Y. Chen, K. Li, X. Liu, J. Zhu, B. Chen, Synlett 2013, 24, 130. b) C.-R. Liu, F.-L.Yang, Y.-Z. Jin, X.-T. Ma, D.-J. Cheng, N. Li, S.-K. Tian, Org. Lett. 2010, 12, 3832. c) Z.-M. Sun, 
S.-P. Chen, P. Zhao, Chem. Eur. J. 2010, 16, 2619. d) C. Li, Y. Zeng, J. Wang, Tetrahedron Lett. 2009, 50, 2956.

4 a) X. Bu, J. Hong, X. Zhou, Adv. Synth. Catal. 2011, 353, 2111. For a similar iron-catalyzed annulation using tertiary benzyl alcohols with alkynes to form 1,1,2,3-substituted indene derivatives, see: b) P Niharika, G Satyanarayana. ChemistrySelect 2018, 3, 289.

5 For selected reviews for regioselective $\mathrm{C}-\mathrm{H}$ functionalization, see: a) C. Sambiagio, D. David Schöbauer, R. Blieck, T. Dao-Huy, G. Pototschnig, P. Schaaf, T. Wiesinger, M. F. Zia, J. Wencel-Delord, T. Besset, B. U. W. Maes, M. Schnürch, Chem. Soc. Rev. 2018, 47, 6603. b) G. Song, X. Li, Acc. Chem. Res. 2015, 48, 1007. c) J. Ye, M. Lautens, Nature Chem. 2015, 7, 863. d) S. De Sarkar, W. Liu, S. I. Kozhushkov, L. Ackermann, Adv. Synth. Catal. 2014, 356, 1461. e) J. Wencel-Delord, F. Glorius, Nat. Chem. 2013, 5, 369. f) D. A. Colby, A. S. Tsai, R. G. Bergman, J. A. Ellman, Acc. Chem. Res. 2012, 45, 814. g) K. M. Engle, T.-S. Mei, M. Wasa, J.-Q. Yu, Acc. Chem. Res. 2012, 45, 788. h) S. H. Cho, SJ. Y. Kim, J. Kwak, S. Chang, Chem. Soc. Rev. 2011, 40, 5068. i) T. Satoh, M. Miura, Chem. Eur. J. 2010, 16, 11212.

6 a) M. Itoh, K. Hirano, T. Satoh, Y. Shibata, K. Tanaka, M. Miura, J. Org. Chem. 2013, 78, 1365. b) K. Morimoto, K. Hirano, T. Satoh, M. Miura, J. Org. Chem. 2011, 76, 9548. c) T. Uto, M. Shimizu, K. Ueura, H. Tsurugi, T. Satoh, M. Miura, J. Org. Chem. 2008, 73, 298. d) Y. Terao, M. Nomoto, T. Satoh, M. Miura, M. Nomura, $J$. Org. Chem. 2004, 69, 6942. e) Y. Terao, H. Wakui, M. Nomoto, T. Satoh, M. Miura, M. Nomura, J. Org. Chem. 2003, 68, 5236. f) Y. Terao, H. Wakui, T. Satoh, M. Miura, M. Nomura, J. Am. Chem. Soc. 2001, 123, 10407.

7 For iridium-catalyzed dehydrative annulation, see: M. Nagamoto, T. Nishimura, Chem. Commun. 2014, 50, 6274.

8 Similar regioselectivity has been observed in Fe-catalyzed annulation (ref. 4a). As suggested in the precedent, a steric factor seems to be important.

9 Even under silver catalysis, the reaction of 1a with aliphatic 4octyne gave a complex mixture including 1:1 and 2:1 coupling products. 


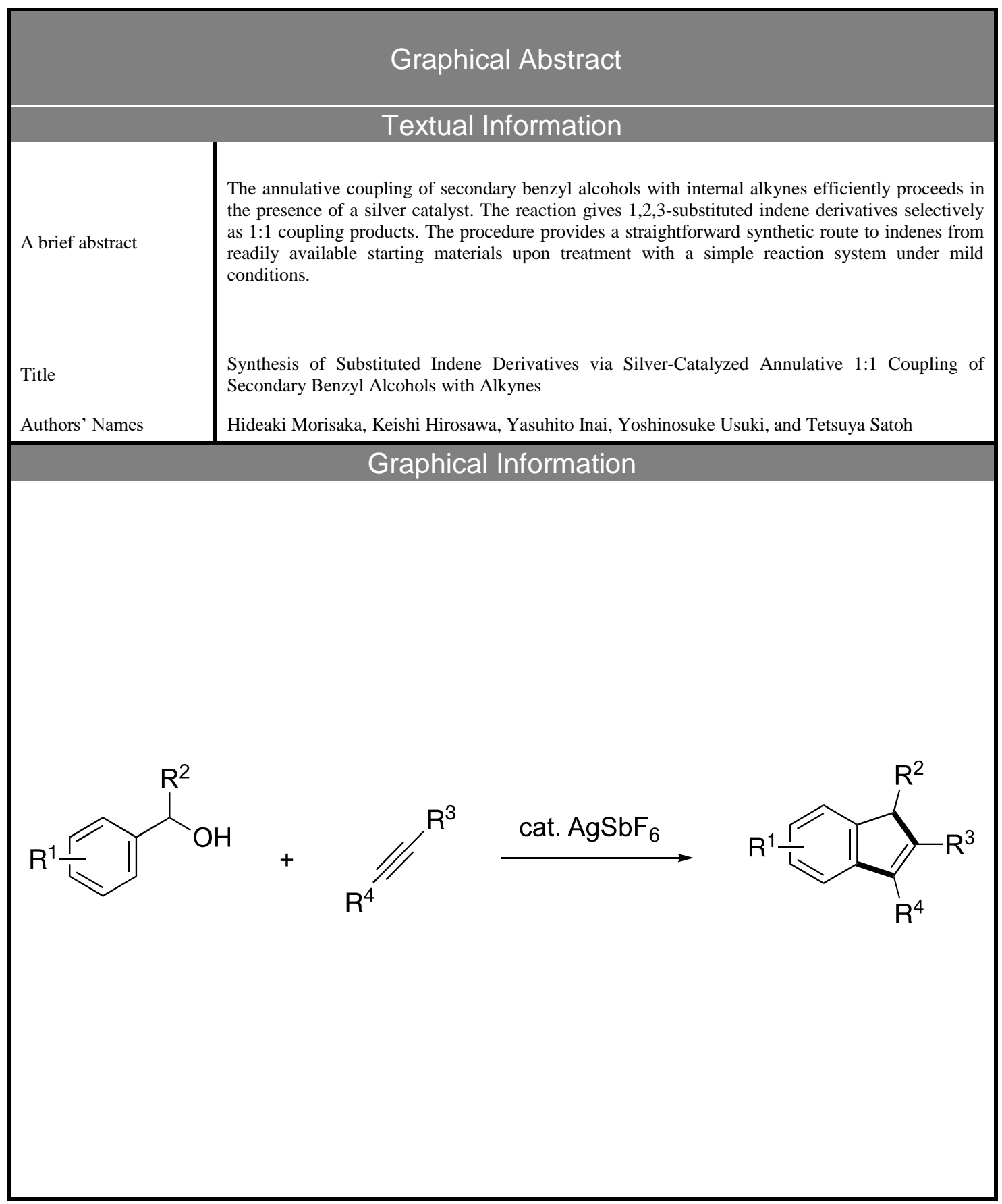

